\title{
What are the needs of people with dementia in acute hospital settings, and what interventions are made to meet these needs? A systematic integrative review of the literature
}

\author{
Janne Røsvik ${ }^{1,2^{*}}$ (D) and Anne Marie Mork Rokstad ${ }^{1,3}$
}

\begin{abstract}
Background: Research aiming to improve the hospital experience for patients with dementia and their informal carers is strongly recommended. The present review aimed to describe the research on interventions to meet the needs of people with dementia in acute hospital settings regarding physical environment, organization of care, and staff knowledge of dementia and competence in person-centred care. An integrative review design was applied. We searched for studies in PubMed, Ovid Medline, Cinahl, Embase, Swemed+, and Cochrane databases using the Mixed Methods Appraisal Tool (MMAT) for quality evaluation. Twenty-seven articles were included, describing the perspectives of people with dementia, informal carers, and professional carers. The MMAT score ranged from two to four. Twelve studies described needs and experiences, mostly using a qualitative design. Common themes and results were synthesized. The studies identified a need to enhance staff competence regarding dementia and person-centred care. Fifteen studies described interventions: two were qualitative; three used mixed method, and 10 were quantitative, of which two were randomized controlled trials and eight were observational studies. Five types of interventions were identified. Three types could positively impact staff knowledge about dementia and person-centred care. One type was experienced as positive regarding organisation of care for patients with dementia. None of the intervention studies found evidence for effects on the identified needs regarding physical environment.
\end{abstract}

Conclusion: The included studies suggest that staff need more knowledge regarding dementia and person-centred dementia care and that training interventions implemented to enhance staff competence had promising results. However, there is a need for research on the needs of patients with dementia in acute hospital settings regarding physical environment and effect of design elements. There is also a scarcity of intervention studies focusing on the effect of models of care that support the psychosocial needs of patients with dementia.

Keywords: Dementia, Acute hospital, Needs, Interventions, Person-centred care, Training, Organisation, Physical environment

\footnotetext{
* Correspondence: janne.rosvik@aldringoghelse.no

'Norwegian National Advisory Unit on Ageing and Health, Vestfold Hospital Trust, Tønsberg, Norway

${ }^{2}$ Department of Geriatric Medicine, Oslo University Hospital-Ullevål, Oslo, Norway

Full list of author information is available at the end of the article
}

(c) The Author(s). 2020 Open Access This article is licensed under a Creative Commons Attribution 4.0 International License, which permits use, sharing, adaptation, distribution and reproduction in any medium or format, as long as you give appropriate credit to the original author(s) and the source, provide a link to the Creative Commons licence, and indicate if changes were made. The images or other third party material in this article are included in the article's Creative Commons licence, unless indicated otherwise in a credit line to the material. If material is not included in the article's Creative Commons licence and your intended use is not permitted by statutory regulation or exceeds the permitted use, you will need to obtain permission directly from the copyright holder. To view a copy of this licence, visit http://creativecommons.org/licenses/by/4.0/ The Creative Commons Public Domain Dedication waiver (http://creativecommons.org/publicdomain/zero/1.0/) applies to the data made available in this article, unless otherwise stated in a credit line to the data. 


\section{Background}

Admission to an acute hospital can be both confusing and frightening for a person with dementia. Even though they are in need of hospital treatment, the stay might have negative impact on their physical, mental and cognitive abilities [1, 2]. As stated by the World Alzheimer's Report 2016, there are significant gaps in health care service research regarding the hospital environment for people with dementia. Research aiming to improve the hospital experience for this group of patients and their informal carers is strongly recommended [3]. Hospitalization of people with dementia often leads to an increase in behavioural and psychological symptoms in dementia, risk of poor outcomes, higher incidence of harm, and further cognitive decline $[1,2,4]$. A prospective cohort study of 10,014 hospital admissions revealed that among people with a dementia diagnosis, delirium occurred in $45.8 \%$ during the hospital stay [5]. Consequences for people with dementia admitted to hospital include higher mortality rates, increased likelihood of falls, functional decline, spatial disorientation, possible malnutrition and dehydration, increased reliance on caregivers, depression, and delirium [1]. Additionally, they may experience more pain, thirst, fear, and over-stimulation than people without a cognitive impairment while in hospital, partly due to their impaired ability to communicate [6]. In acute hospitals the level of activity is high, therefore, monitoring and managing patients' acute needs is a first priority for staff [7].

The concept 'dementia-friendly hospital' is linked to the elements focused on in the concept of 'elder-friendly hospitals': social climate, policy and procedures, care systems and processes, and physical design [8]. Both principles for universal design [9] and for dementia-friendly design [10] have been used to guide new construction and the refurbishment of existing hospitals. Universal access or design means to design and compose an environment so that it can be "accessed, understood and used to the greatest extent possible by all people regardless of their age, size, ability or disability" [9]. The scoping review of Parke and colleagues (2017) focused on the impact of design and architectural features on the independent function of hospitalized older people with dementia. They concluded that intervention studies are lacking in this area and recommended physical design changes to produce positive impacts on people with dementia in an acute care setting [11].

Several countries have developed national guidelines stating that person-centred care should be the basis of care for people with dementia $[12,13]$. The most widely used and recognized person-centred care approach is the care philosophy of social psychologist Tom Kitwood [14]. This philosophy has four key elements: 1) valuing people with dementia and those who care for them, 2) treating people as individuals, 3) looking at the world from the perspective of the person with dementia, and 4) a positive social environment in which the person living with dementia can experience relative well-being [15]. Like the dementia-friendly hospital concept, this philosophy underlines that the physical and social environment should support people with dementia. Providing person-centred care implies to identify and respond to the individual needs and preferences of the person with dementia, their carer(s) and family. The meta-synthesis of Turner and colleagues (2017) underlined the importance of person-centred care for people with dementia in general hospitals, pointed out a gap between actual and desired practice, and highlighted a need for more education and training [16]. Fessey's (2007) study described a lack of understanding of personcentred care among hospital nursing staff and found that application of such knowledge in practice was heavily influenced by the care environment [17].

The need for staff competence and skills in dementia care is underlined by informal caregivers. A systematic review made by Beardon and colleagues (2018) summarized informal carers' experiences of acute hospital care aiming to inform best practice service delivery. According to the informal caregivers, there is a need for improvement in staff training to develop staff's capability to provide help with personal care needs and to safeguard older patients' dignity [18].

The aim of the present study was to review the documented needs of people with dementia in acute hospital settings as experienced by the patients, the informal caregivers and staff regarding the following three aspects: the physical environment, organization of care, and staff knowledge of dementia and competence in person-centred care. Furthermore, we aimed to describe the interventions made to meet these needs. The research questions were: 1 ) What are the needs and experiences of people with dementia as described by the patients, their informal caregivers, and staff? 2) What interventions are described? and 3) How are the needs and experiences reflected in the results of the interventions?

\section{Methods}

An integrative literature review was found to be a suitable method as this type of review is deemed appropriate when there is change in a trend or direction of a phenomenon [19]. An integrative review summarizes past empirical or theoretical literature to provide a more comprehensive understanding of the phenomenon [20]. The approach allows for the inclusion of diverse methodologies, both empirical and theoretical, in order to present varied perspectives on the subject of concern [20-22] and promote a holistic conceptualization [19].

\section{Search strategy}

Searches were made in PubMed, Ovid Medline, Cinahl, Embase, Swemed+, and the Cochrane databases with no 
constraints regarding year of publication. The search terms were selected after testing a great amount of terms. The authors cooperated with a specialized librarian in the testing. Both MeSH terms, terms used in the aim and research questions of the present study and terms found in relevant articles were used. The terms were tested in different combinations and as truncated. The search terms that resulted in relevant articles were chosen. We used the following search terms: hospital OR inpatient AND dementia OR Alzheimer" OR cognitive impairment AND physical environment / staff training OR staff education OR staff / person centred OR person centred/patient transfer* OR care pathway OR organization of care OR transitional care, screening titles and abstracts. The search was conducted March 5th 2018 and updated May 15th 2020.

\section{Study selection}

The two reviewing authors (JR and AMMR) screened the abstracts of all papers. A data extraction form based on the inclusion and exclusion criteria was used to select studies that were relevant to include in the full-text screening. As this is an integrative review, both qualitative, quantitative, and mixed method studies were eligible for inclusion. The following inclusion criteria were used: the studies should 1) describe care for people with cognitive impairment and/or dementia in an acute hospital setting, 2) focus on the physical environment, staff competence in dementia or person-centred care, or organisation of care, 3) be published in English in a peerreviewed publication, 4) present a clear research question or objective, and 5) describe the methods used to address the research question or objective. Studies focusing solely on discharge from hospital were excluded. Reviews, reports, commentaries, editorials, letters to the editor, and books were also excluded. The same procedure and data extraction form was used for the screening of the full texts of the selected studies. The results of the screenings were compared and reasons for disagreements were discussed and resolved.

\section{Quality assessment}

The quality of the papers that were found to be relevant based on the full-text screening was assessed by the Mixed Methods Appraisal Tool (MMAT) [23, 24]. This screening provides a set of criteria for appraising the methodological quality of quantitative, qualitative, and mixed methods studies concomitantly. The MMAT checklist includes two screening questions that are applied across all relevant study designs. Both screening questions must be answered 'yes' for a paper to be qualified for inclusion and further quality screening. The studies are then systematically reviewed and rated according to how each stage of the method implementation, the quality of the sample, and the validation of the results of the different types of study designs (qualitative research, randomized controlled trials, non-randomized studies, quantitative descriptive studies, and mixed methods studies) are described. A study can achieve a score from one to four. In the current review, papers with a score of two or more were included.

To achieve inter-rater agreement, the two authors reviewed eight papers independently. The scores were compared, reasons for disagreements discussed, and agreement reached on principles for the further use of the MMAT criteria. The inter-rater agreement was $85 \%$ and considered as good. Following this initial inter-rater agreement test, the remaining papers were divided into two batches and reviewed independently by the researchers. In cases of doubt, the reviewers consulted each other and came to an agreement.

\section{Analysis}

The analysis builds on the steps described by Whittemore and Knafl (2005) who state that the goals of the data analysis of an integrative review is "a thorough and unbiased interpretation of primary sources, along with an innovative synthesis of the evidence" (page 505) [22]. It is also pointed out that analytical methods are a poorly developed part of integrative reviews. A constant comparison method is recommended because it facilitates the distinction of patterns, themes, variations, and relationships. This implies the comparison of extracted data in order to categorize similar data. Coded categories are then compared to further the analysis and synthesis process. This approach is compatible with the integrative review's use of data from diverse methodologies and consists of: data reduction, data display, data comparison, conclusion drawing, and verification [22].

In the present study, a table was used to present a summary of characteristics of each included article: author(s), publication year, aim, country, study design, participants, outcomes, results, conclusion and data quality score. The included papers were inspected and divided into two subgroups by a predetermined conceptual classification derived from the research questions of this review: Subgroup A consisted of studies that explored the needs and experiences of people with dementia, their informal carers, and staff in acute hospital settings. Subgroup B contained papers that described the results of intervention studies (Tables 1 and 2).

Next, the findings of the studies in each subgroup were analysed and themes were identified (see Table 3). Data extracted from subgroup A reflected needs, conditions that were found to be of importance to meet needs, and positive and negative experiences related to the categories described in the aim of the present study (physical environment, competence of dementia and person-centred dementia care, organization and management of care). A constant comparative process was undertaken to synthesize the 


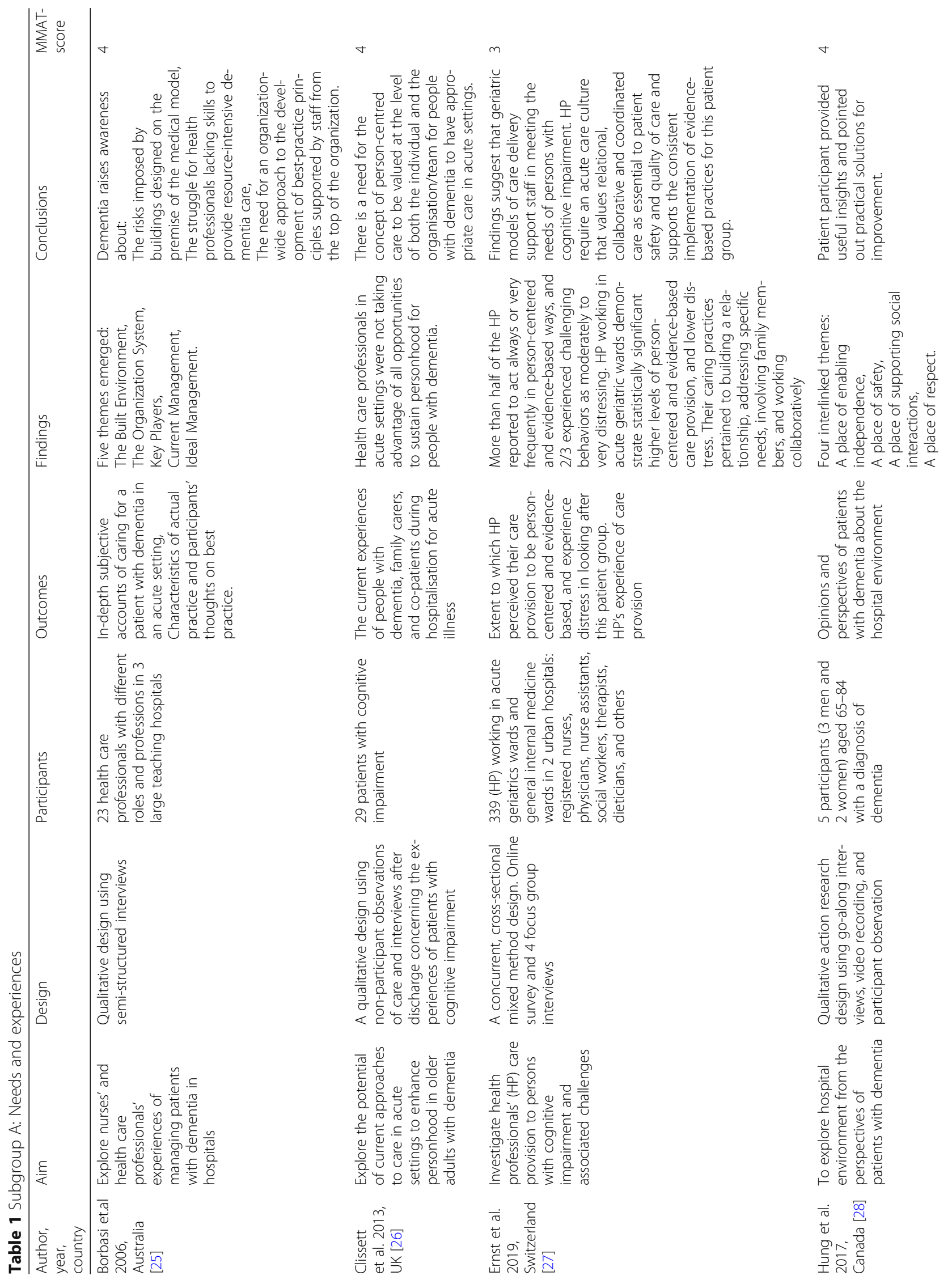




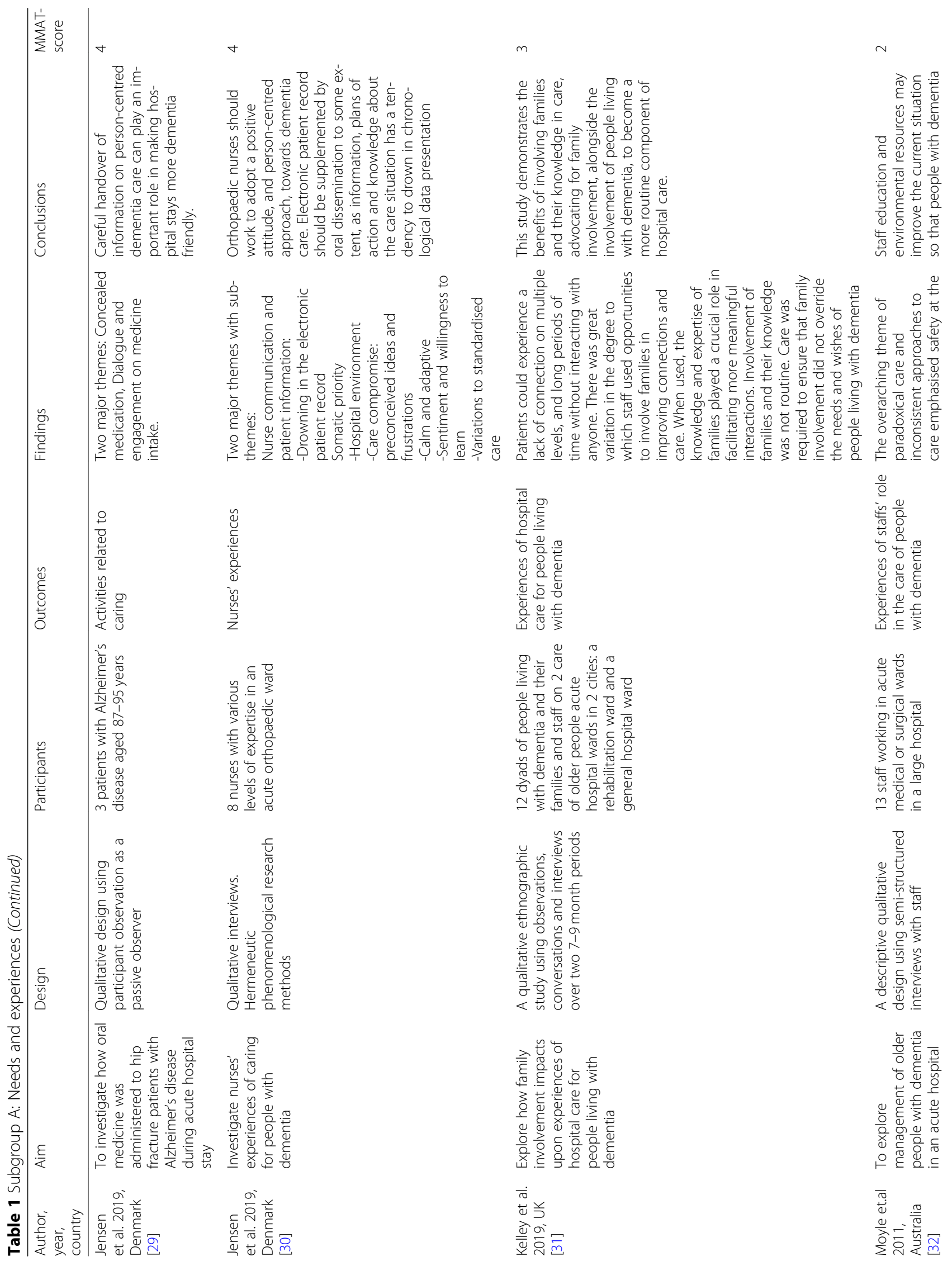




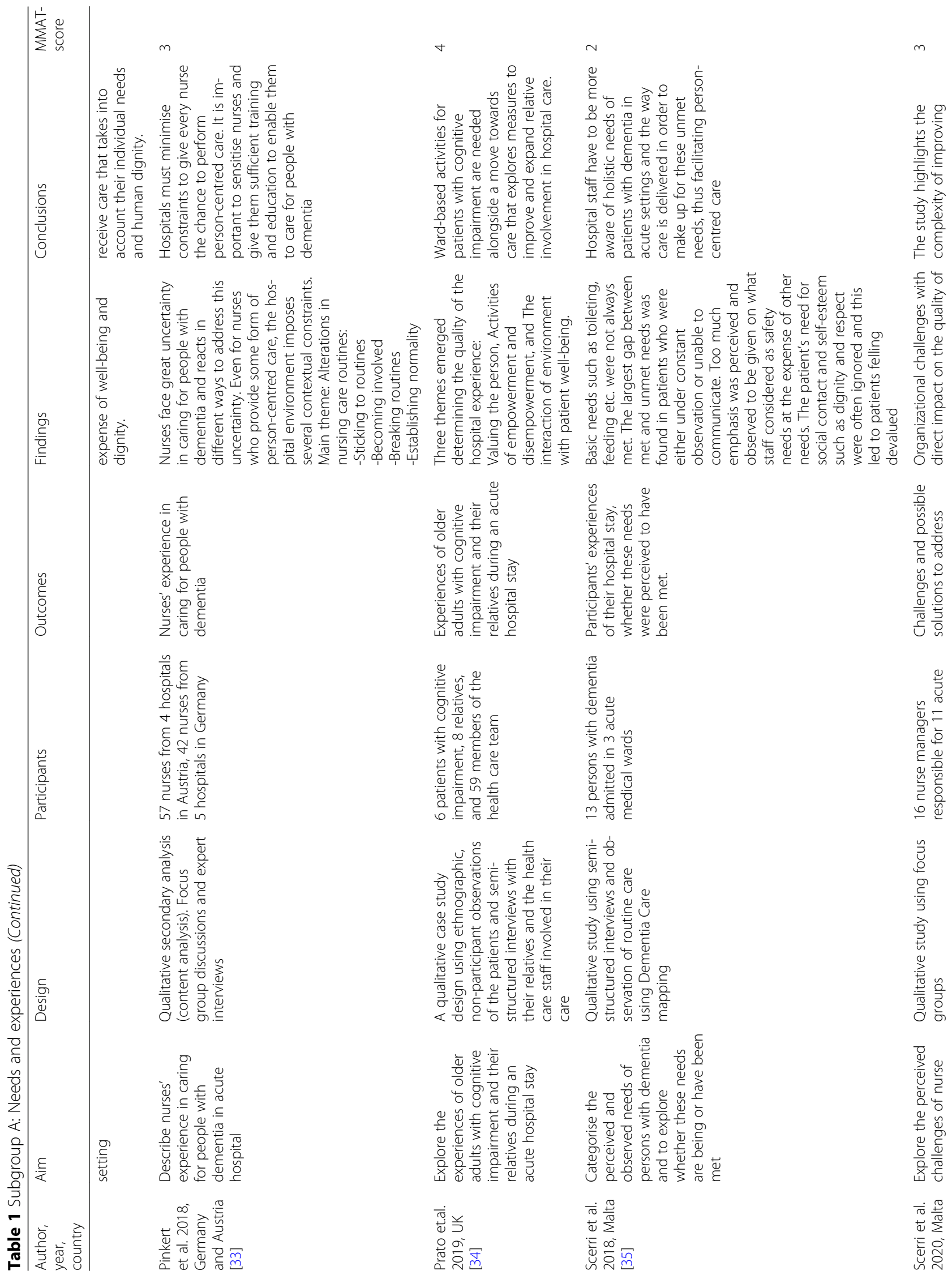




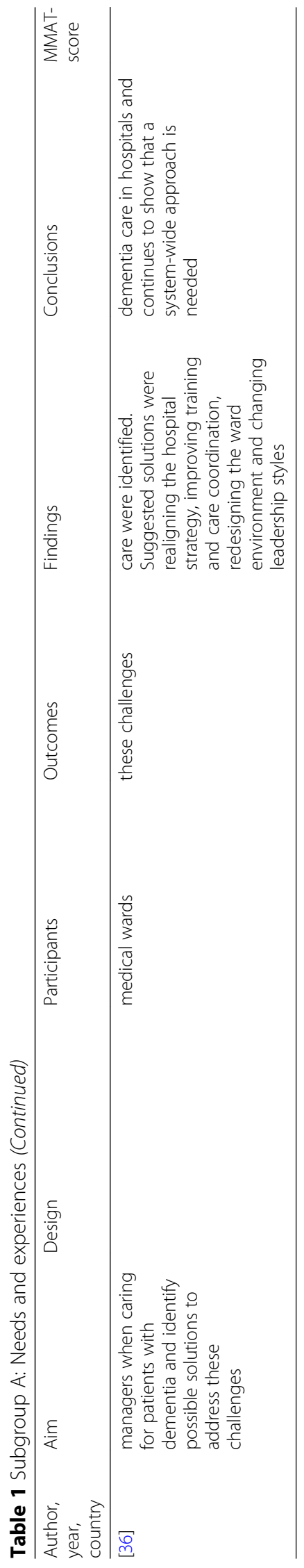




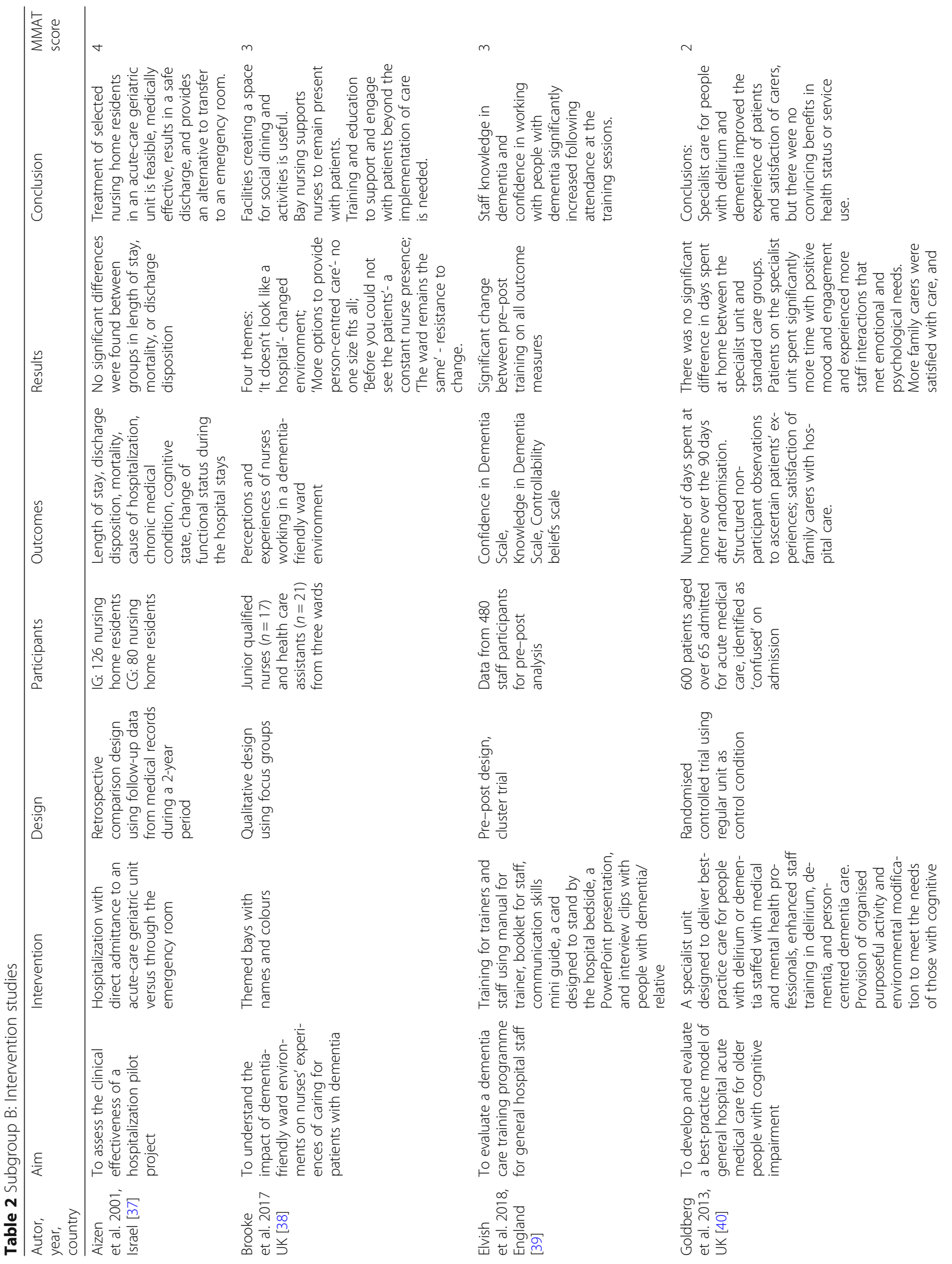




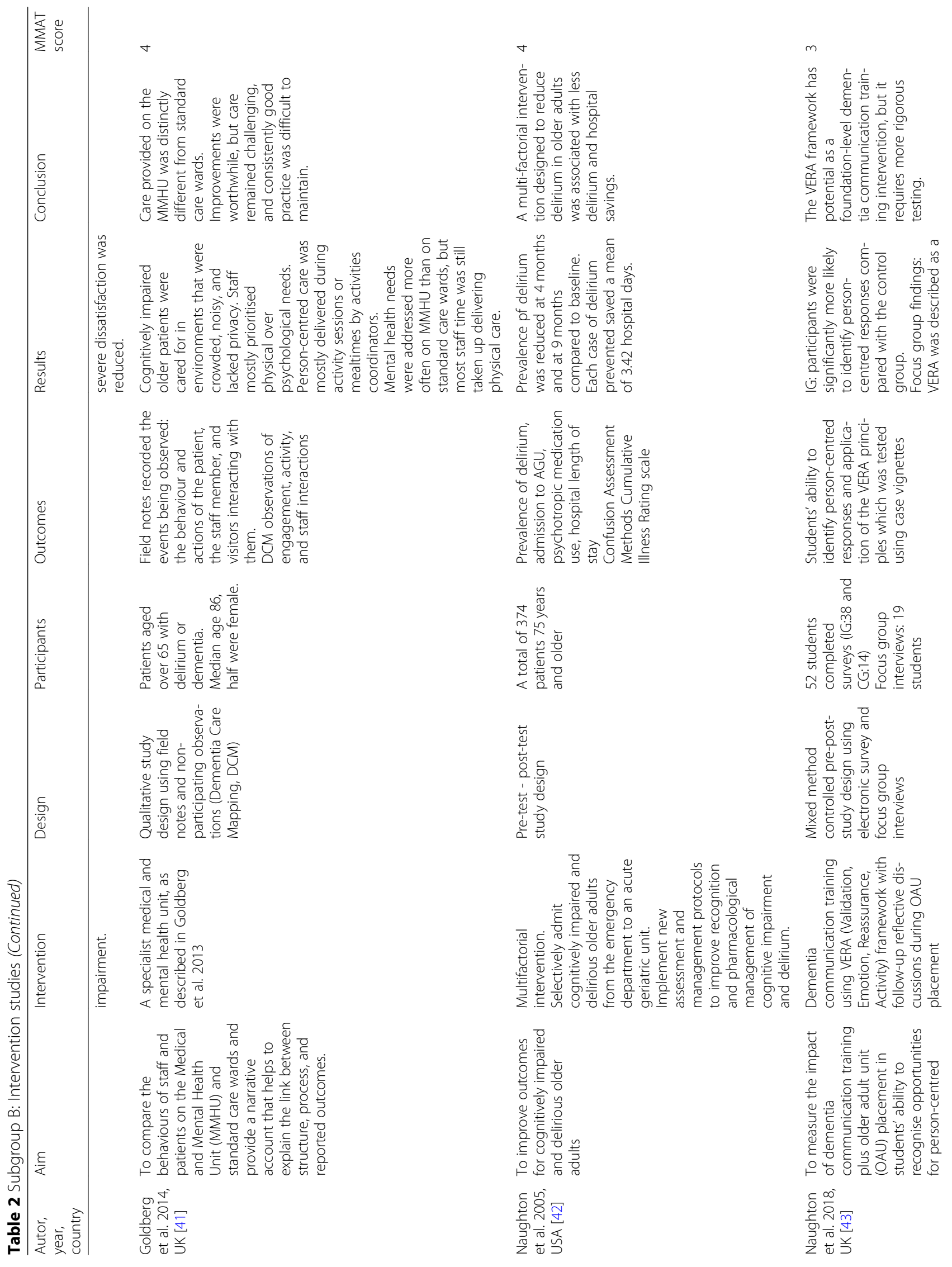




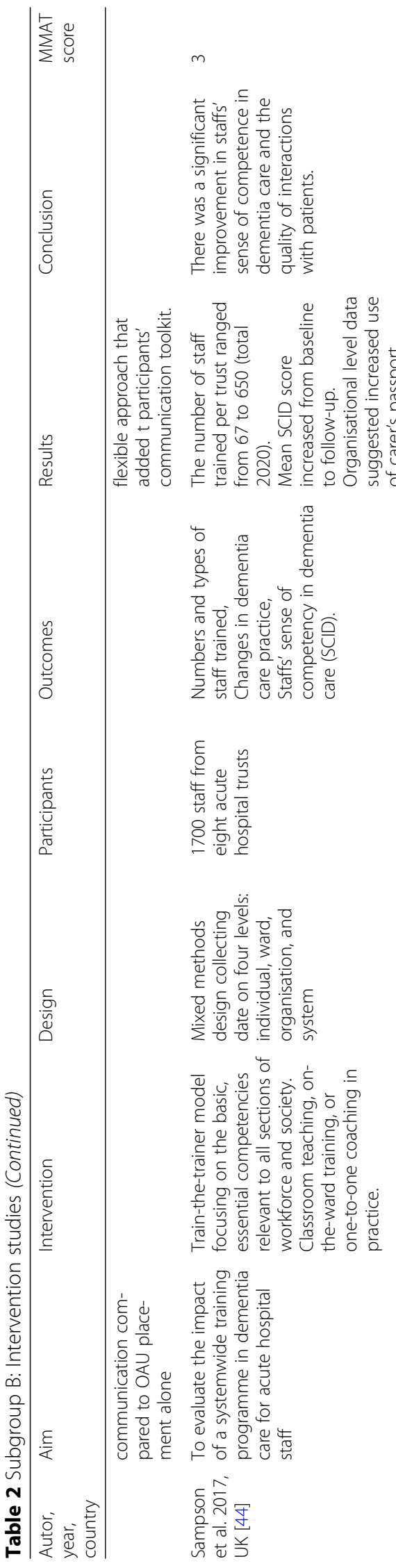

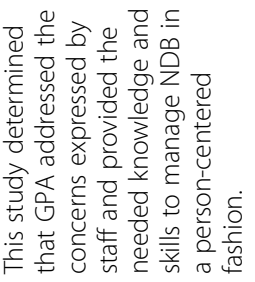
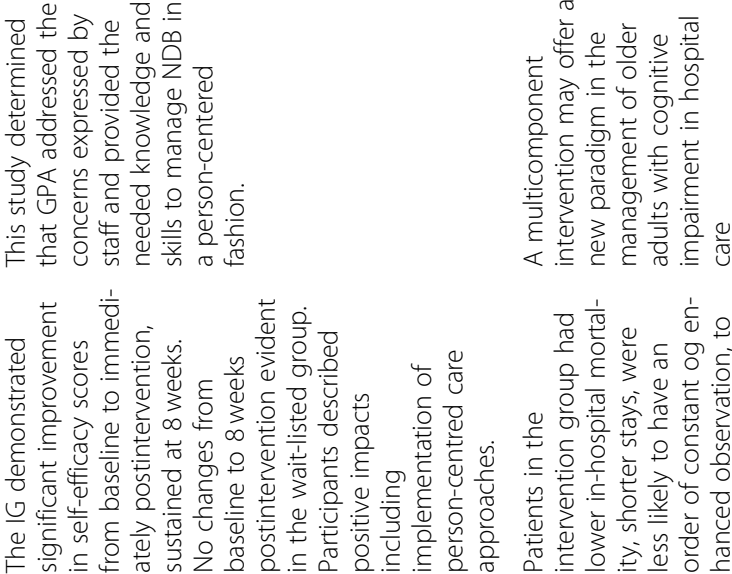

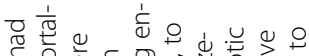

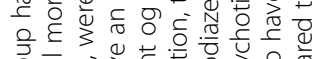

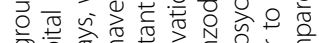

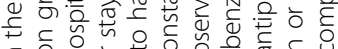

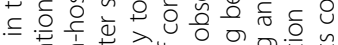

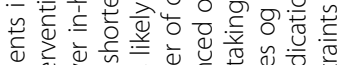

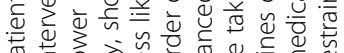

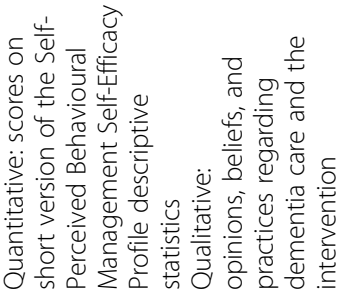

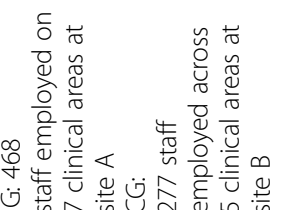

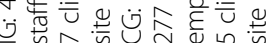

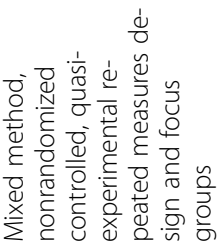

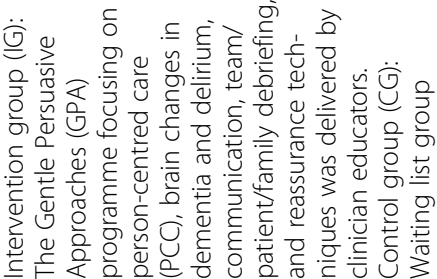

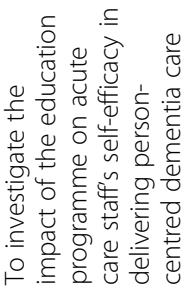

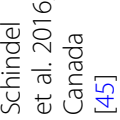

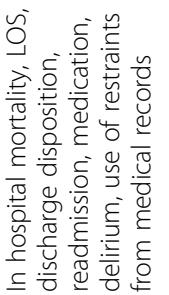

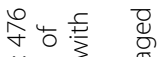

它造语

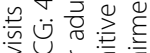

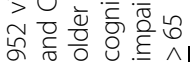
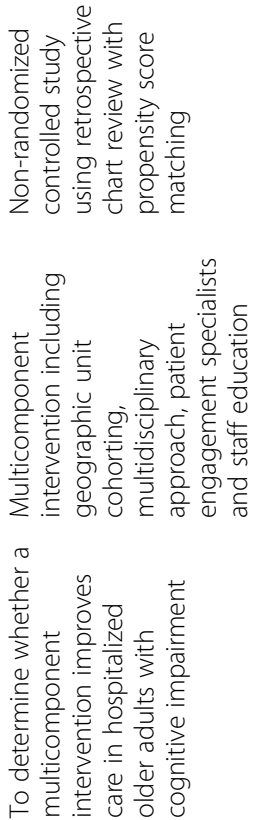

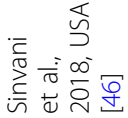




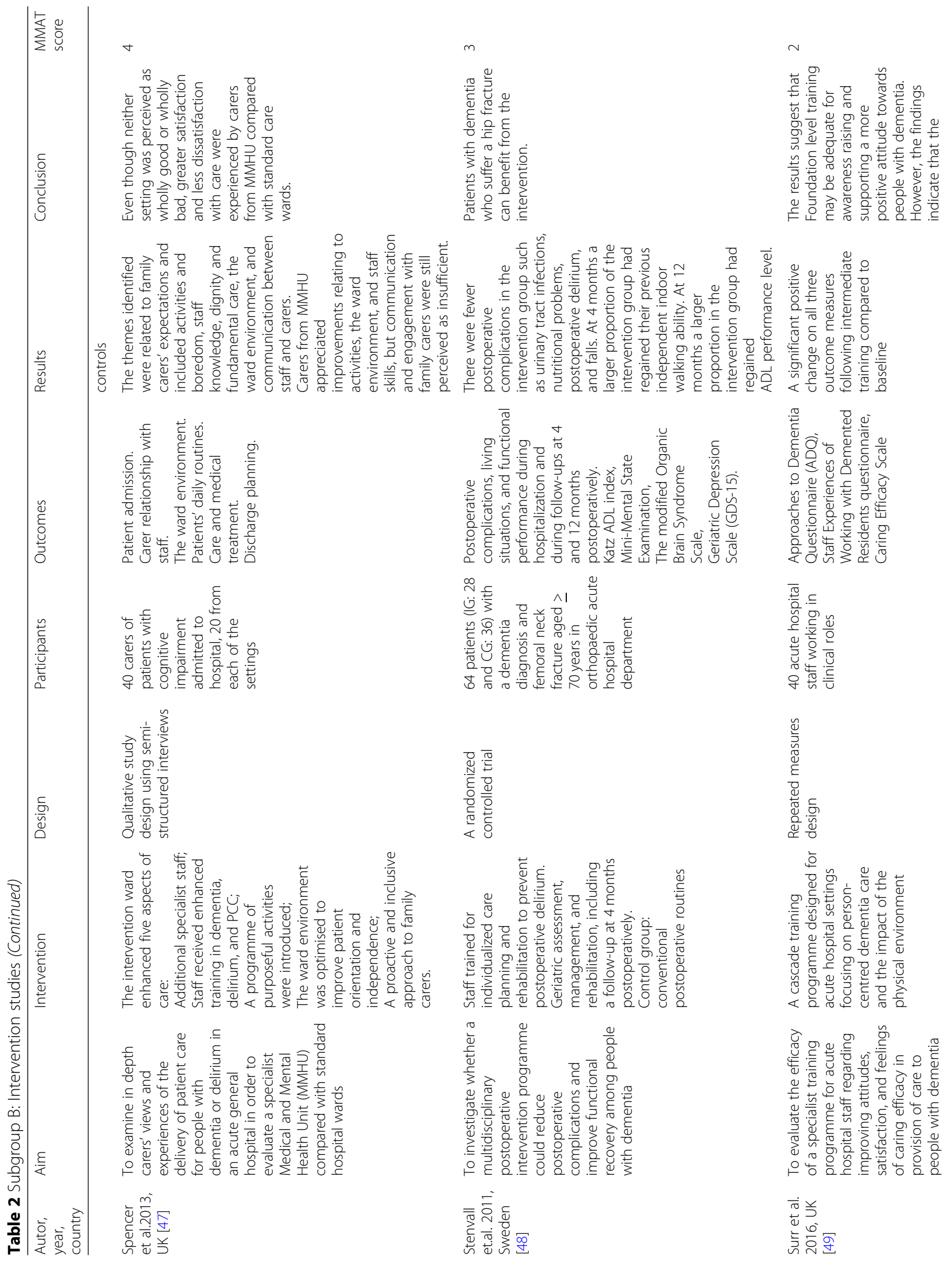




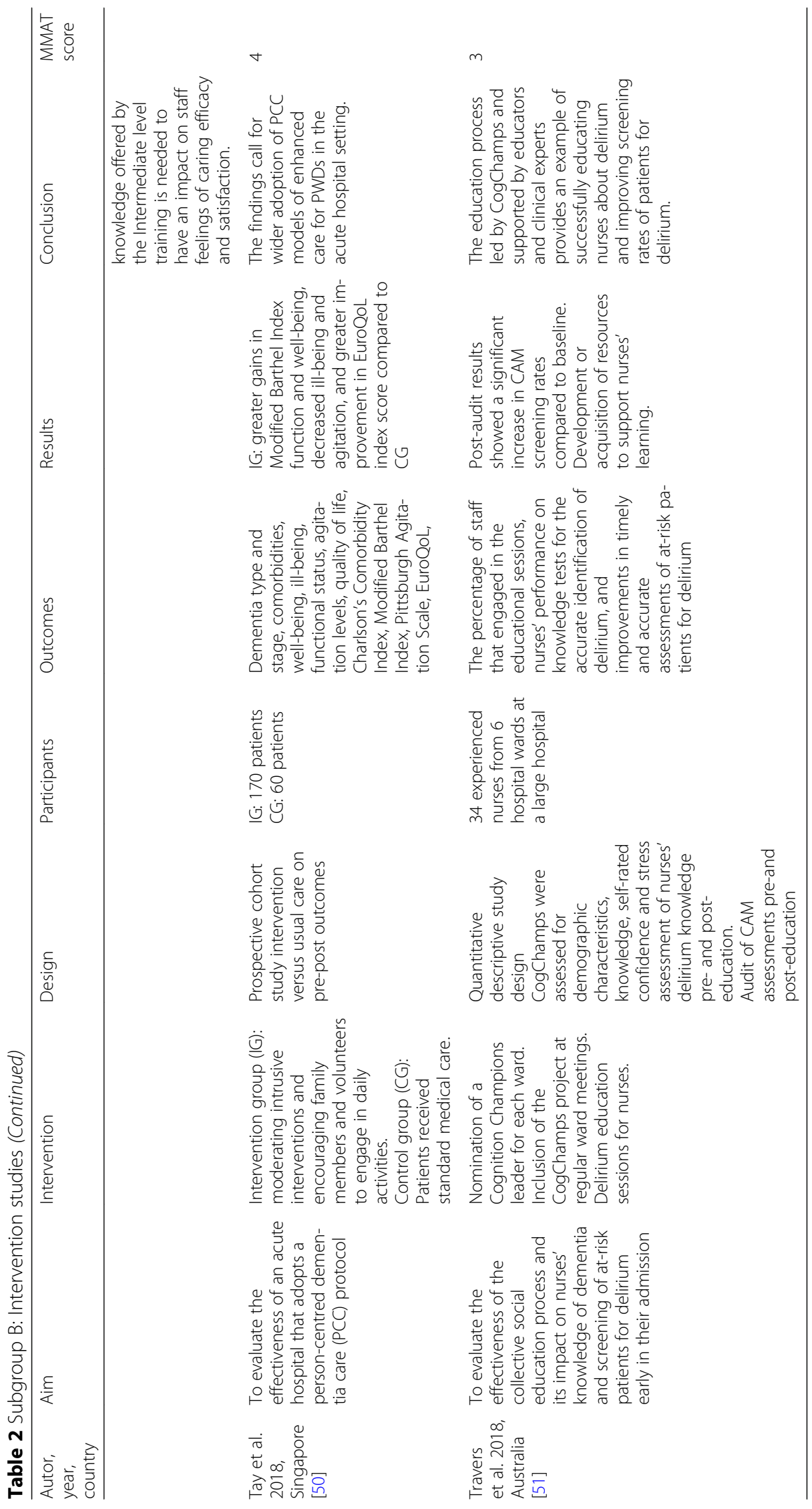


Table 3 Subgroups A and B with themes and types of interventions

\begin{tabular}{|c|c|}
\hline Categories & Themes \\
\hline \multicolumn{2}{|c|}{ Subgroup A: Needs and experiences } \\
\hline Physical environment & $\begin{array}{l}\text { 1) the importance for independence and orientation of an environment that is easy to navigate, has } \\
\text { distinguishable features and a view of the outdoors, } \\
\text { 2) staff's experience of the physical environment as a barrier for patient safety. }\end{array}$ \\
\hline $\begin{array}{l}\text { Organization and } \\
\text { management of care }\end{array}$ & $\begin{array}{l}\text { 1) the need for best practice principles in dementia hospital care, } \\
\text { 2) hospital staff need more knowledge and better skills regarding dementia care, } \\
\text { 3) staff's experience of the agitation of patients with dementia as burdensome, } \\
\text { 4) the need for continuity of staff to support basic psychological needs, } \\
\text { 5) the need for social inclusion in order to feel respected, } \\
\text { 6) the need to be consulted regarding their own care to maintain dignity, } \\
\text { 7) the need for meaningful interaction with staff to feel safe, and } \\
\text { 8) the importance of staff knowing patient backgrounds to enhance empowerment. }\end{array}$ \\
\hline $\begin{array}{l}\text { Competence and person- } \\
\text { centred care }\end{array}$ & $\begin{array}{l}\text { 1) the importance of companionship with other patients for a positive experience of hospitalization, } \\
\text { 2) the importance of prioritizing the needs and care of confused patients to avoid worsening dementia-related } \\
\text { symptoms, and } \\
\text { 3) the importance of appropriate buildings and competent staff for quality care and prevention of the use of } \\
\text { restraints. }\end{array}$ \\
\hline
\end{tabular}

Subgroup B: Types of interventions

1) Implementation of physical changes in the environment $(n=1)$

2) Comprehensive train-the-trainer programmes $(n=4)$

3) Teaching and reflection $(n=2)$

4) Moderation of intrusive medical interventions $(n=1)$

5) Special geriatric models $(n=5)$

extracted data for each category into themes, and to verify that the emerging themes were grounded in the data of the primary sources [22]. Both authors validated the final themes in order to enhance trustworthiness.

The intervention studies in subgroup B were analysed in order to identify patterns based on the focus of the interventions, i.e. what had been done to meet the needs of patients with cognitive impairment in the hospital wards. The emerging patterns were used to classify the interventions into groups that constituted types of interventions. The results of the studies were described in a summary for each type of intervention.

For both subgroups, the perspectives included in the syntheses of results were described, i.e., whether the findings were based on the perspectives of patients with dementia, informal caregivers, staff, or all of these.

Last, a juxtaposition was made of how the identified needs and experiences were reflected in the results of the implemented interventions for each category.

The analysis process was conducted primarily by the first author with input from the second author. The analyses were discussed and validated by the two authors, who agreed on the final categorizations, themes, and interpretation.

\section{Results}

The first search yielded 691 non-duplicate articles. Of these, 20 articles fit the inclusion criteria. Seven articles were added in the updated search. See Fig. 1 for a flow diagram of the article selection process. Of the 27 articles included, 12 were studies that described needs or experiences (subgroup A, see Table 1). Three of these studies were from the
United Kingdom (UK), two from Australia, Malta and Denmark respectively. Canada, Germany/ Austria, and Switzerland had one study each. One of these studies used mixed method, the others used qualitative design. Four studies interviewed only patients with dementia. One study interviewed patients with dementia and their informal carers, one interviewed patients, informal carers and staff. Staff were interviewed in six studies. One study used observation of care, four used both observation of care and interviews with patients with dementia. The MMAT score of the studies in subgroup A ranged from 2 to 4.

Fifteen studies described interventions (subgroup B, see Table 2). Eight of these studies were from the UK, two were from USA. Singapore, Canada, Australia, Israel, and Sweden had one study each. Two studies used qualitative design; three used mixed method, and 10 were quantitative. Five types of interventions were identified: implementation of physical changes in the environment [38], comprehensive train-the-trainer programmes [44, 45, 51, 52], teaching and reflection [43, 49], moderation of intrusive medical interventions [50], and special geriatric model [37, 41, 42, 46-48]. The MMAT score of the studies in subgroup B ranged from 2 to 4 .

\section{Physical environment Needs and experiences}

Eight studies described needs and experiences related to this category. The synthesis of the findings resulted in two themes: 1) the importance for independence and orientation of an environment that is easy to navigate, 


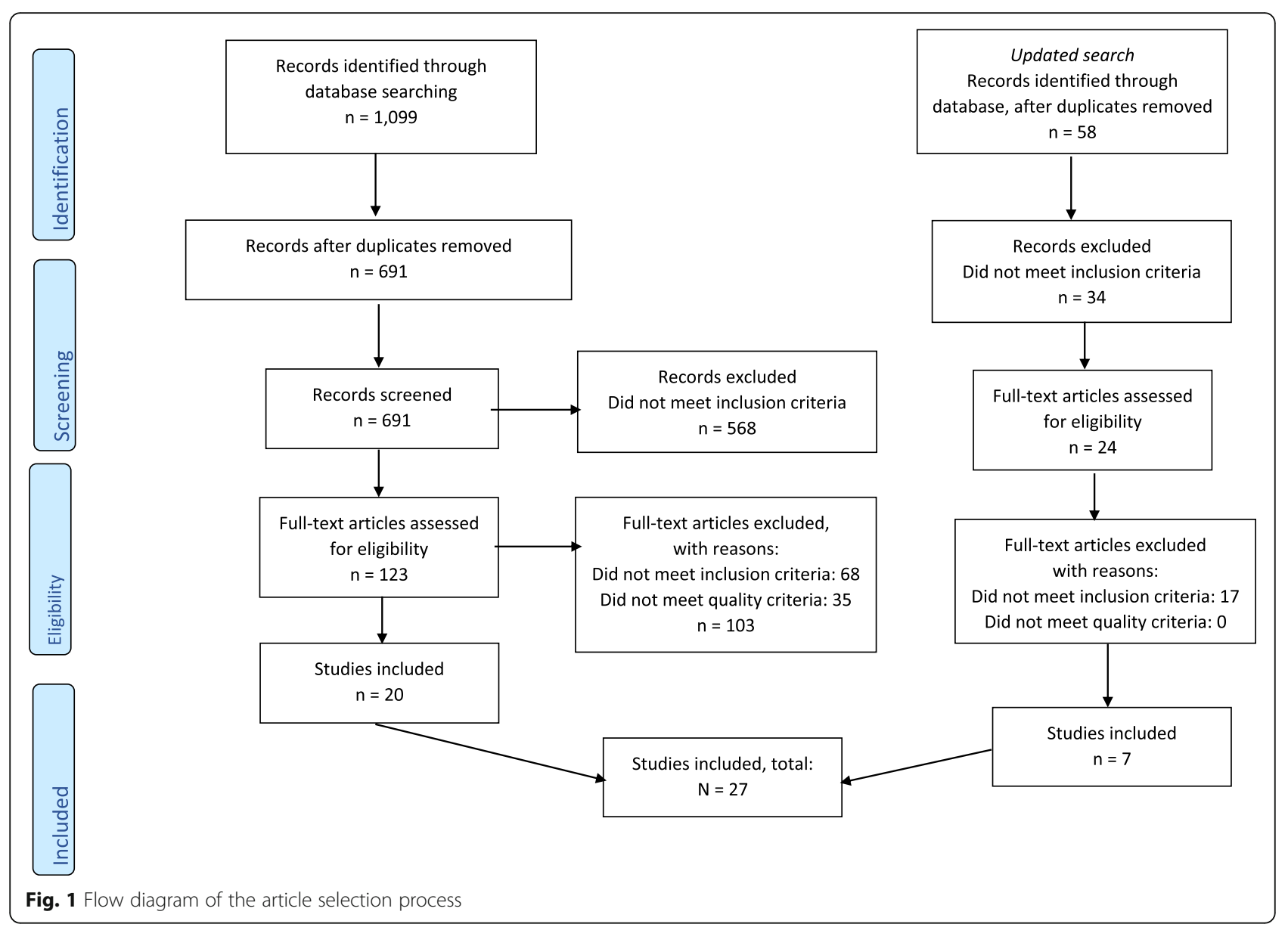

has distinguishable features and a view of the outdoors, and 2) staff's experience of the physical environment as a barrier for patient safety.

Experiences and needs of patients with dementia related to the physical environment in acute hospital wards were described from the perspective of staff [25, $29,33-36]$ persons with dementia [28, 34, 46], family carers [34] and by observations [31, 35]. The studies demonstrate the importance of an environment that enables independence for people with cognitive impairment by making it easier to navigate the surroundings. The physical environment in acute hospital wards was described as chaotic, noisy, crowded and potentially confusing for people with cognitive impairment, [29, 31, 35, 36] and a dementia friendly design with homelike environment was highly recommended for better orientation [33]. Windows were important to orientate patients in time and space $[25,34]$. Distinguishable features were needed [25, 36], as some environmental conditions represented problems for patients with dementia. Bathrooms located too far from the bay area made it difficult for patients with orientation difficulties to find their way to the toilets [25]. Identical room doors and nondistinguishable hallways made it difficult for them to find their rooms. Dark areas and glare on the floor increased the risk of falling and overcrowding with equipment in the corridors made it difficult to use the handrails on the wall. This evoked feelings of danger and acute risk in the patients [28].

The acute hospital environment impacted on care delivery and staff's attitudes and behaviours. Staff's focus on safety and patient security in the acute hospital setting was found to be excessive, with unnatural monitoring of patients, preventing them from leaving the ward, and little emphasis on basic nursing care and meaningful interaction. Hence, the patients' need for preserving dignity was at risk of being overlooked in the pursuit of safety as defined by staff $[32,35]$. The opportunities for interaction, stimulation and orientating features facilitated by the environment was sparse, which made people with dementia less capable of making sense of the unfamiliar surroundings [31]. For the patient, safety meant not only being physically safe but also emotionally safe [28].

\section{Interventions}

Two types of interventions reported results related to the physical environment: 1) implementation of physical 
changes in the environment, and 2) comprehensive trainthe-trainer programmes in dementia care.

The study that implemented physical changes in the environment took the following actions: organized the wards into themed bays, introduced an activity room, used pictures and distinct colours, and obstructed the view from the windows in the ward. The reason for applying opaque transfers on the windows was not explained in the article. The actions taken to improve the environment were evaluated in focus group interviews with staff. They expressed positive experiences with the intervention as they believed that the actions supported interaction with patients and relatives and increased their knowledge and understanding of them from a perspective other than the provision of clinical information. They experienced that the actions supported person-centred care. The organization of wards into themed bays increased the presence of staff, brought staff in closer contact with the patients, and created better opportunities to make running observations of the patients. However, some staff stated that the impact of the interventions on care were limited or negative [38].

The second intervention study introduced a train-thetrainer programme based on person-centred care and encouraging changes in the physical environment as part of the programme. The results assessed by observations indicated that merely encouraging trainers to focus on the physical environment and propose changes to make it fit better with the needs of patients with dementia had limited impact [44].

\section{How needs and experiences are reflected in the results of interventions}

The intervention implementation of physical changes in the environment [38] reflected the identified importance of having a view of the outdoors. The study reported that obstruction of the view had negative effects on patients' orientation [38]. None of the other types of interventions reported results that can be used to inform decisions on making physical hospital environments dementia friendly.

\section{Competence of dementia and person-centred dementia care}

\section{Needs and experiences}

The syntheses of the results of studies exploring experiences and the need for competence and person-centred dementia care in acute hospitals revealed the following list of themes: 1) the need for best practice principles in dementia hospital care, 2) hospital staff need more knowledge and better skills regarding dementia care, 3) staffs experience of the agitation of patients with dementia as burdensome, 4) the need for continuity of staff to support basic psychological needs, 5) the need for social inclusion in order to feel respected, 6) the need to be consulted regarding their own care to maintain dignity, 7) the need for meaningful interaction with staff to feel safe, and 8) the importance of staff knowing patient backgrounds to enhance empowerment.

The findings in these studies were based on the perspective of staff [25, 27-30,32-34, 36], experiences from the perspective of persons with dementia and informal carers [30, 32, 34, 35, 39], and observations [27, 32, 34, 35].

The lack of skills in hospital staff and the lack of best practice principles and guidelines were described $[25,29]$. Because of staff's generally insufficient skills in how to care for people with dementia, there was a need for better care delivery to these patients. Staff were often unable to distinguish between acute and chronic confusion and were unsure of how to assess or treat dementia and delirium. Staff expressed their frustration and concern at needing to manage agitated patients with dementia [32]. Observations of interactions between staff and patients revealed that communication could be polite and kind, but it was often functional- and task orientated. There seemed to be a priority of somatic health leading to a just-enough and justin-time approach to the psychosocial aspects of personcentred care [29]. To meet the needs of persons with dementia for genuine connections to feel safe, staff's communication skills should be improved to enhance meaningful interaction [31]. Examples of communications skills in dementia care are to make eye contact before you talk to the person, take into account that the person may need longer time to comprehend what is said and to respond, and act in a manner that conveys respect and creates a friendly atmosphere [34]. The key features that enhanced or diminished a sense of attachment and inclusion for persons with dementia were those of continuity of staff and staffs communication skills. How the staff perceived the relationship with and the perspective of the patient was also important [27, 33]. Furthermore, the way staff took opportunities to engage with the patients, enhance a trustworthy relationship and demonstrate the importance of their welfare and involvement in decision making was crucial in supporting these psychological needs $[26,27,35]$. Using the preferred name to address the individual and allowing them to use their personal belongings were important for supporting people with dementia's sense of identity. The research revealed little evidence that staff engage people with dementia in activities and support their need for occupation [35]. The lack of available activities in the hospital setting lead to boredom and frustration for people with dementia [34, 35]. Facilitating simple day-to-day activities such as going for a walk or meeting someone for conversation is essential for enhancing health and well-being by supporting feelings of social connection, independence, purpose, and a sense of belonging in the world [28]. To become involved with patients with dementia, staff must 
stray from familiar routines and become creative to meet individual needs [31, 33].

Additionally, limited evidence of the promotion of comfort was demonstrated. For staff, patients' physical discomfort took precedence over emotional discomfort. There was little evidence of nursing staff viewing distressed behaviours as symptoms of discomfort. Staff tended not to act in a person-centred, proactive manner to address primary needs like hunger and thirst, nor to use sensory interventions like music or human touch to promote psychological comfort [26].

To feel respected, patients with dementia need to be socially included, however, people with dementia experienced being excluded or discriminated against due to the changes in their cognitive function. The label of dementia could lead to a feeling of being a subclass on the ward [28]. Patients with dementia were often assumed to be incapable of making care decisions. The staff tended to seek the opinion of family caregivers only, which was a serious threat to the person with dementia's dignity and rights as the perspective of the family was not necessarily the same as that of the patient [28].

The importance of staff having life-story information to enable them to value the patient was demonstrated. However, the research revealed that staff limited their knowledge of the patients with dementia to everyday information. The staff was seen by family caregivers as mainly task orientated. This had a negative impact on the relatives' hospital experience. Family caregivers were important agents for the empowerment of patients with cognitive impairment, and they were vital for maintaining the patients' personhood [32, 34].

\section{Interventions}

Studies of interventions to improve staff's competence in dementia care and promote person-centred dementia care in acute hospital settings included comprehensive trainthe-trainer programmes and teaching and reflection interventions. In the train-the-trainer programmes, a group of trainers received courses focusing on delirium assessment [44, 51], dementia and person-centred care principles [45], and communication skills [39]. In turn, these trainers trained and supported the hospital staff. The teaching and reflection interventions were conducted as a personcentred care training programme for all hospital staff [49] and face-to-face dementia training including reflection [43]. The intervention outcomes were evaluated from the perspective of staff [2, 39, 45, 49] nursing students [43], observations [44], and post-audit results [51].

Evaluations of one train-the-trainer programme showed improvement in staff's self-reported knowledge about dementia and an increase in their confidence in working with people with dementia [39]. Another study revealed a small increase in competence, the largest related to building relationships and initiating interaction with patients [44] as well as for delirium screening rates [51]. Furthermore, staff expressed that there was a positive impact on the implementation of person-centred care approaches, and increased effectiveness in their practice [45]. A change in staff s interpretation and understanding of patients' challenging behaviour was demonstrated [39]. The evaluation of the teaching and reflection intervention used to increase knowledge and enhance person-centred care indicated that the intervention can improve staff attitudes towards people with dementia and increase staffs perceived caring efficacy [49]. Nursing students reported increased competence in connecting with patients and were significantly more likely to identify person-centred responses [43].

\section{How needs and experiences are reflected in the results of interventions}

Four types of interventions produced results that reflected the identified needs and experiences regarding competence and person-centred care. Comprehensive train-the-trainer programmes and implementation of physical changes in the environment demonstrated results that were relevant for the patients' need for meaningful interaction with ward staff to experience genuine connection [38, 44]. The need for more knowledge and better skills regarding dementia care in hospital staff was reflected in the results of comprehensive train-thetrainer programmes and special geriatric models [44, 45]. Results from the latter also indicated that this type of intervention is relevant for the patients' need for care that supports their basic psychological needs [40, 47]. Teaching and reflection interventions and comprehensive train-the-trainer programmes demonstrated results indicating positive impact on staff attitudes towards patients with dementia who were agitated $[2,39,45,49]$.

There were no results reflecting the other four identified needs and experiences in this category.

\section{Organisation \\ Needs and experiences}

From the syntheses of findings in the studies exploring the experiences and needs related organization of health care for people with dementia in acute hospitals, the following themes emerged: 1) the importance of companionship with other patients for a positive experience of hospitalization, 2) the importance of prioritizing the needs and care of confused patients to avoid worsening dementia-related symptoms, and 3) the importance of appropriate buildings and competent staff for quality care and prevention of the use of restraints.

The identified studies took, the perspective of staff, $[25,29,32,33,36,40]$ people with dementia and informal caregivers [32, 34] and included observation [32]. According to staff's experiences, the time they spent 
with patients with dementia made a real difference to the patients' well-being because vigilant and continual observation and assessment were crucial for the patient to experience safety, especially at night [25]. People with dementia and informal caregivers commented on the constraining impact of the ward routine on the patient's experience. Being isolated in a single room without the positive impact of the company of other patients in a common area was experienced negatively. Furthermore, relatives commented on the inability of patients with cognitive impairment to adapt to the ward environment if moved around within the hospital [34]. The focus of care in hospitals was strongly geared towards acute problems, and, hence, persons with dementia were viewed as low-priority cases [32]. People with dementia were prone to be overlooked in the busy world of nurses. The inability of patients to provide a full history of events added to the complexity of care in an acute condition seemed to worsen dementia-related symptoms [25]. Fragmentation of care was demonstrated, like lack of coordination and information sharing during transitions or in planning therapeutic and diagnostic interventions [27]. Inadequate hospital systems and routines were seen as barriers for meeting the needs of people with dementia [27, 29, 31]. Furthermore, inappropriate building design and limited staff knowledge and understanding of dementia as major constraints to best practice [33], and consequently, the use of restraints was reported in each setting [25].

\section{Interventions}

Eight papers describing a total of seven interventions to facilitate the organisation of acute hospital services for people with dementia were identified. The interventions focused on different special geriatric models: organizing special geriatric units or use of comprehensive geriatric assessment $[40,41,43,46-48,50]$. These interventions also included staff training on dementia care. The outcomes were reported from the perspective of people with dementia [40, 48], informal caregivers $[40,47]$ proxy-based assessment using standardized questionnaires [37, 42, 50], observations $[41,46]$ and data from patient records [46].

According to observations, patients in units using special geriatric models spent significantly more time with positive moods and engagement, were able to walk around more freely, and experienced more staff interactions that met their emotional and psychological needs compared to other wards. A randomized, controlled study using a multidisciplinary postoperative intervention programme with teams applying comprehensive geriatric assessment found fewer postoperative complications in the intervention group [48]. However, most staff time was still taken up delivering physical care [41]. The studies exploring family caregivers' satisfaction with care in special geriatric units revealed both less dissatisfaction [47] and more satisfaction with care [40] compared to standard care wards. Additionally, evaluation of special geriatric unit models revealed lower in-hospital mortality, shorter stays, less need for constant or enhanced observations, reduced use of psychotropic medication and occurrence of delirium compared to standard wards $[42,46]$. Evaluation of the effectiveness of an acute hospital dementia unit adopting a person-centred care protocol moderating intrusive interventions revealed positive impacts on quality of life such as decreased agitation in people with dementia and confirmed cost-effectiveness [50]. The evaluation of the effect of using direct admittance to an acute-care geriatric unit versus an ordinary emergency room showed no impact on characteristics of the hospital stay such as length of stay, mortality, or discharge disposition [37].

\section{How needs and experiences are reflected in the results of interventions}

The results of implementation of special geriatric models and moderating intrusive interventions reflected the described importance of prioritizing the needs and care of confused patients. Informal carers were reported to be more satisfied with care in units implementing these types of interventions than informal carers in regular units; quality of life improved; agitation in people with dementia decreased $[40,47,50]$, and there were fewer postoperative infections [48]. These types of interventions implied the need for more staff with enhanced knowledge and skills in dementia care, which is relevant for the described importance of competent staff for quality care and prevention of the use of restraints [40, 43, 47]. The importance of companionship with other patients to a positive experience of hospitalization for people with dementia was not reflected in the results of any of the types of interventions.

\section{Discussion}

The present review found limited research regarding the needs of people with dementia in acute hospital settings and of the effect of interventions implemented to meet these needs.

Regarding the category physical hospital environment, all respondent groups-patients with dementia, their informal carers, and staff-underlined the importance of environmental features that helped the patients orientate in time and space. However, few intervention studies focusing on the physical hospital environment were identified, which is in line with the results of the review of Parke and colleagues (2017) [11]. Some features of a dementiafriendly hospital have been outlined [53], but it is not clear which specific physical design elements can maximize functional ability and improve independence in patients with dementia, while at the same time enhancing their 
safety in acute hospital units. The review of Marquardt and colleagues (2014) identified 169 studies on the impact of the design of the environment on people with dementia in long-term care facilities. According to this review, the physical environment can help people with dementia to preserve and improve their well-being, behaviour, independence, and functioning [54]. It remains to be affirmed whether corresponding physical design changes are feasible and have the same positive impact in an acute hospital ward. More research is needed to establish how design elements influence outcomes at the individual and system levels in the acute hospital. Staff differed from the other respondent groups in the present review by their focus on the barriers to patient safety represented by inappropriate buildings. Staff also deviated from the patients and informal carers regarding the category competence in dementia and person-centred care by not having the same focus on the psychological needs of patients with dementia. These findings correspond with earlier research which showed that staff lacked understanding of person-centred care and that application of such knowledge was heavily influenced by the care environment and high demands on staff $[7$, 17]. All respondent groups in the present review agreed that staff's knowledge of dementia and communication skills needed to be enhanced, which is in line with the review of Beardon and colleagues (2018) [18]. This result may, at least partly, explain staff's lack of focus on personcentred care. Because of insufficient knowledge about dementia, staff may not be aware that the way they communicate with the patient can influence the patients' psychosocial needs and, in turn, the patient's behaviour and safety. The results of the studies in this category indicate that different types of staff training interventions can enhance staff knowledge of dementia.

Patients and informal carers pointed to activities and social inclusion as important for the ability of people with dementia to express their needs and for prevention of behavioural symptoms. None of the included intervention studies reported results that were directly relevant to this finding. Lack of opportunities for social interaction has been described as a problem in previous research [18]. There is little tradition for setting aside time and resources for social activities in the acute hospital. The physical design of the hospital ward seldom facilitates such activities, which reflects a model of care that is not tuned in to the special needs of patients with dementia. The results of the studies in the category organization showed that the needs and care of confused patients were not prioritized in acute hospital wards; the wards were strongly geared towards acute medical problems. As the number and percentage of patients with dementia increase, adopting a form of organisation that takes their special need for social inclusion and activity into account should be considered as this may promote well-being and prevent agitation. Competent staff was a key element in the special care model interventions of the included studies, which reported positive effects on psychotropic medication use (reduction), delirium, and informal carers' satisfaction with care. However, not even these models had resources such as staff, time, space, and equipment designated to support the need of patients with dementia for activity and social inclusion. The present review found no studies that evaluated a form of organization or model of care designed to prevent behavioural symptoms of dementia by implementing social activities in an acute hospital ward.

\section{Methodological considerations}

Only papers reported in English were included, therefore, information regarding hospital care for people with dementia reported in other languages is not accounted for.

The present review does not include studies on discharge and transfer from hospital to community care or other health care services. These aspects of the hospitalization process are important for patients with dementia and their informal carers. However, this review describes three extensive areas, adding a fourth area would make the scope too broad for one review.

The narrow range of scores on the MMAT, two as the lowest accepted score, four the maximum score, illustrates the limitation of this tool in differentiating the quality of the included studies. However, the MMAT permits concomitant appraisal and description of the methodological quality in qualitative, quantitative, and mixed-method studies, which was considered a strength in the current review.

Almost equal numbers of quantitative and qualitative studies were included, which gives a broad view of the situation regarding needs, experiences, and effects.

\section{Conclusions}

The included studies suggest that staff need more knowledge of dementia and person-centred dementia care and that training intervention studies to enhance staff competence show promising results. However, there is a need for research on the needs of patients with dementia in acute hospital settings regarding physical environment and effect of design elements. There is also a scarcity of intervention studies focusing on the effects of models of care that support the psychosocial needs of patients with dementia.

\section{Supplementary information}

Supplementary information accompanies this paper at https://doi.org/10. 1186/s12913-020-05618-3.

\section{Additional file 1}




\section{Abbreviations}

MMAT: The Mixed Methods Appraisal Tool; UK: United Kingdom

\section{Acknowledgements}

The authors extend their gratitude to librarian Vigdis Knutsen who performed the literature searches and professor emeritus Knut Engedal who read and commented on the manuscript.

\section{Authors' contributions}

JR and AMMR designed the study, screened all abstracts and full text articles and selected the studies that were included. JR analysed and interpreted the data in close cooperation with AMMR. AMMR wrote the result section, JR wrote the other sections, but both authors discussed and were major contributors in the writing of all parts of the manuscript. JR and AMMR read and approved the final manuscript.

\section{Authors' information}

(Not applicable).

\section{Funding}

The study was funded by Norwegian National Advisory Unit on Ageing and Health. Both authors are employed by the funder, but the funding body did not have any role in the design of the study and collection, analysis, and interpretation of data and in writing the manuscript.

\section{Availability of data and materials}

The datasets used and/or analysed during the current study are available from the corresponding author on reasonable request.

\section{Ethics approval and consent to participate}

(Not applicable).

\section{Consent for publication}

(Not applicable)

\section{Competing interests}

The authors declare that they have no competing interests.

\section{Author details}

${ }^{1}$ Norwegian National Advisory Unit on Ageing and Health, Vestfold Hospital Trust, Tønsberg, Norway. ${ }^{2}$ Department of Geriatric Medicine, Oslo University Hospital-Ullevål, Oslo, Norway. ${ }^{3}$ Faculty of Health Sciences and Social Care, Molde University College, Molde, Norway.

\section{Received: 9 January 2020 Accepted: 2 August 2020}

Published online: 07 August 2020

\section{References}

1. Dewing J, Dijk S. What is the current state of care for older people with dementia in general hospitals? A literature review. Dementia. 2016;15(1):106-24.

2. Sampson EL, White N, Leurent B, Scott S, Lord K, Round J, et al. Behavioural and psychiatric symptoms in people with dementia admitted to the acute hospital: prospective cohort study. Br J Psychiatry. 2014;205(3):189-96.

3. Prince M, Comas-Herrera A, Knapp M, Guerchet M, Karagiannidou M. World Alzheimer report 2016: improving healthcare for people living with dementia: coverage, quality and costs now and in the future. London: Alzheimer's Disease International (ADI); 2016

4. Hermann DM, Muck S, Nehen HG. Supporting dementia patients in hospital environments: health-related risks, needs and dedicated structures for patient care. Eur J Neurol. 2015:22(2):239-45 e17-8.

5. Reynish EL, Hapca SM, De Souza N, Cvoro V, Donnan PT, Guthrie B. Epidemiology and outcomes of people with dementia, delirium, and unspecified cognitive impairment in the general hospital: prospective cohort study of 10,014 admissions. BMC Med. 2017;15(1):140.

6. Bridges J, Wilkinson C. Achieving dignity for older people with dementia in hospital. Nurs Stand. 2011;25(29):42-7 quiz 8.

7. Royal College of Nursing. RCN Development Programme: Transforming Dementia Care in Hospitals. 2014

8. Parke B, Chappell N. Transactions between older people and the hospital environment: a social ecological analysis. J Aging Stud. 2010;24:115-24.
9. Center for Excellence in Universal Design. What is universal design: The 7 principles. 2014.

10. Dementia Services Development Centre. Design for people with dementia: an overview of building design regulators. Stirling: University of Stirling, Dementia Services; 2013.

11. Parke B, Boltz M, Hunter KF, Chambers T, Wolf-Ostermann K, Adi MN, et al. A scoping literature review of dementia-friendly hospital design. Gerontologist. 2017;57(4):e62-74.

12. National Institute for Health and Care Excellence (NICE). In: (NICE) NIfHaCE, editor. Dementia: assessment, management and support for people living with dementia and their carers. NICE guideline [NG97]. UK: National Institute for Health and Care Excellence (NICE); 2018.

13. Laver K, Cumming RG, Dyer SM, Agar MR, Anstey KJ, Beattie E, et al. Clinical practice guidelines for dementia in Australia. Med J Aust. 2016;204(5):191-3.

14. Kitwood T. Dementia reconsidered: The person comes first. Berkshire: Open University Press; 1997.

15. Brooker D. Person-centred dementia care: making services better. London: Jessica Kingsley; 2007.

16. Turner A, Eccles FJR, Elvish R, Simpson J, Keady J. The experience of caring for patients with dementia within a general hospital setting: a metasynthesis of the qualitative literature. Aging Ment Health. 2017;21(1):66-76.

17. Fessey V. Patients who present with dementia: exploring the knowledge of hospital nurses. Nurs Old People. 2007;19(10):29-33.

18. Beardon S, Patel K, Davies B, Ward H. Informal carers' perspectives on the delivery of acute hospital care for patients with dementia: a systematic review. BMC Geriatr. 2018;18(1):23.

19. Torraco RJ. Writing integrative literature reviews: guidelines and examples. Hum Resour Dev Rev. 2005·4:356-67.

20. Broome ME. In: Rodgers BL, Knafl KA, editors. Integrative literature reviews for the development of concepts. 2nd ed. Philadelphia: W.B. Saunders Company; 1993.

21. Kirkevold M. Integrative nursing research - an important strategy to further the development of nursing science and nursing practice. J Adv Nurs. 1997; 25:977-84.

22. Whittemore R, Knafl K. The integrative review: updated methodology. J Adv Nurs. 2005;52(5):546-53.

23. Pluye P, Gagnon MP, Griffiths F, Johnson-Lafleur J. A scoring system for appraising mixed methods research, and concomitantly appraising qualitative, quantitative and mixed methods primary studies in mixed studies reviews. Int J Nurs Stud. 2009;46(4):529-46.

24. Pluye P, Robert E, Cargo M, Bartlett G, O'Cathain A, Griffiths F, et al. Proposal: A mixed methods appraisal tool for systematic mixed studies reviews. 2011.

25. Borbasi S, Jones J, Lockwood C, Emden C. Health professionals' perspectives of providing care to people with dementia in the acute setting: toward better practice. Geriatr Nurs. 2006;27(5):300-8.

26. Clissett P, Porock D, Harwood RH, Gladman JR. The challenges of achieving person-centred care in acute hospitals: a qualitative study of people with dementia and their families. Int J Nurs Stud. 2013:50(11):1495-503.

27. Ernst J, Petry H, Luethi N, Naef R. Acute care delivery to persons with cognitive impairment: a mixed method study of health professionals' care provision and associated challenges. Aging Ment Health. 2019;23:1-10.

28. Hung L, Phinney A, Chaudhury H, Rodney P, Tabamo J, Bohl D. "Little things matter!" Exploring the perspectives of patients with dementia about the hospital environment. Int J Old People Nurs. 2017:12(3):e12153.

29. Jensen AM, Pedersen BD, Wilson RL, Bang Olsen R, Hounsgaard L. Nurses' experiences of delivering acute orthopaedic care to patients with dementia. Int J Older People Nursing. 2019;14(4):e12271.

30. Jensen AM, Pedersen BD, Olsen RB, Hounsgaard L. Medication and care in Alzheimer's patients in the acute care setting: a qualitative analysis. Dementia. 2019;18(6):2173-88.

31. Kelley R, Godfrey M, Young J. The impacts of family involvement on general hospital care experiences for people living with dementia: an ethnographic study. Int J Nurs Stud. 2019;96:72-81.

32. Moyle W, Borbasi S, Wallis M, Olorenshaw R, Gracia N. Acute care management of older people with dementia: a qualitative perspective. $J$ Clin Nurs. 2011;20(3-4):420-8

33. Pinkert C, Faul E, Saxer S, Burgstaller M, Kamleitner D, Mayer H. Experiences of nurses with the care of patients with dementia in acute hospitals: a secondary analysis. J Clin Nurs. 2018:27(1-2):162-72.

34. Prato L, Lindley L, Boyles M, Robinson L, Abley C. Empowerment, environment and person-centred care: a qualitative study exploring the hospital experience for adults with cognitive impairment. Dementia. 2019;18(7-8):2710-30. 
35. Scerri A, Scerri C, Innes A. The perceived and observed needs of patients with dementia admitted to acute medical wards. Dementia. 2018;27:1471301218814383.

36. Scerri A, Innes A, Scerri C. Dementia care in acute hospitals-a qualitative study on nurse managers' perceived challenges and solutions. J Nurs Manag. 2020;28(2):399-406.

37. Aizen E, Swartzman R, Clarfield AM. Hospitalization of nursing home residents in an acute-care geriatric department: direct versus emergency room admission. Israel Med Assoc J. 2001;3(10):734-8.

38. Brooke J, Semlyen J. Exploring the impact of dementia-friendly ward environments on the provision of care: A qualitative thematic analysis. Dementia. 2017;18:1471301216689402.

39. Elvish R, Burrow S, Cawley R, Harney K, Pilling M, Gregory J, et al. 'Getting to know Me': the second phase roll-out of a staff training programme for supporting people with dementia in general hospitals. Dementia. 2018;17(1):96-109.

40. Goldberg SE, Bradshaw LE, Kearney FC, Russell C, Whittamore KH, Foster PE, et al. Care in specialist medical and mental health unit compared with standard care for older people with cognitive impairment admitted to general hospital: randomised controlled trial (NIHR TEAM trial). BMJ. 2013;347:f4132

41. Goldberg SE, Whittamore KH, Pollock K, Harwood RH, Gladman JR. Caring for cognitively impaired older patients in the general hospital: a qualitative analysis of similarities and differences between a specialist medical and mental health unit and standard care wards. Int J Nurs Stud. 2014;51(10):1332-43.

42. Naughton BJ, Saltzman S, Ramadan F, Chadha N, Priore R, Mylotte JM. A multifactorial intervention to reduce prevalence of delirium and shorten hospital length of stay. J Am Geriatr Soc. 2005;53(1):18-23.

43. Naughton C, Beard C, Tzouvara V, Pegram A, Verity R, Eley R, et al. A feasibility study of dementia communication training based on the VERA framework for pre-registration nurses: part II impact on student experience. Nurse Educ Today. 2018;63:87-93.

44. Sampson EL, Vickerstaff V, Lietz S, Orrell M. Improving the care of people with dementia in general hospitals: evaluation of a whole-system train-thetrainer model. Int Psychogeriatr. 2017;29(4):605-14.

45. Schindel Martin L, Gillies L, Coker E, Pizzacalla A, Montemuro M, Suva G, et al. An education intervention to enhance staff self-efficacy to provide dementia Care in an Acute Care Hospital in Canada. Am J Alzheimers Dis Other Dement. 2016;31(8):664-77.

46. Sinvani L, Warner-Cohen J, Strunk A, Halbert T, Harisingani R, Mulvany C, et al. A multicomponent model to improve Hospital Care of Older Adults with cognitive impairment: a propensity score-matched analysis. J Am Geriatr Soc. 2018;66(9):1700-7.

47. Spencer K, Foster P, Whittamore KH, Goldberg SE, Harwood RH. Delivering dementia care differently--evaluating the differences and similarities between a specialist medical and mental health unit and standard acute care wards: a qualitative study of family carers' perceptions of quality of care. BMJ Open. 2013;3(12):e004198.

48. Stenvall M, Berggren M, Lundstrom M, Gustafson Y, Olofsson B. A multidisciplinary intervention program improved the outcome after hip fracture for people with dementia-Subgroup analyses of a randomized controlled trial. Arch Gerontol Geriatr. 2011;54:e284-9.

49. Surr CA, Smith SJ, Crossland J, Robins J. Impact of a person-centred dementia care training programme on hospital staff attitudes, role efficacy and perceptions of caring for people with dementia: a repeated measures study. Int J Nurs Stud. 2016;53:144-51.

50. Tay FHE, Thompson CL, Nieh CM, Nieh CC, Koh HM, Tan JJC, et al. Personcentered care for older people with dementia in the acute hospital. Alzheimers Dement. 2018:4:19-27.

51. Travers C, Henderson A, Graham F, Beattie E. Turning education into action: impact of a collective social education approach to improve nurses' ability to recognize and accurately assess delirium in hospitalized older patients. Nurse Educ Today. 2018;62:91-7.

52. Elvish R, Burrow S, Cawley R, Harney K, Graham P, Pilling M, et al. 'Getting to know Me': the development and evaluation of a training programme for enhancing skills in the care of people with dementia in general hospital settings. Aging Ment Health. 2014;18(4):481-8.

53. Waller S, Masterson A. Designing dementia-friendly hospital environments. Future Hosp J. 2015;2(1):63-8.

54. Marquardt G, Bueter K, Motzek T. Impact of the design of the built environment on people with dementia: an evidence-based review. HERD. 2014;8(1):127-57.

\section{Publisher's Note}

Springer Nature remains neutral with regard to jurisdictional claims in published maps and institutional affiliations.
Ready to submit your research? Choose BMC and benefit from:

- fast, convenient online submission

- thorough peer review by experienced researchers in your field

- rapid publication on acceptance

- support for research data, including large and complex data types

- gold Open Access which fosters wider collaboration and increased citations

- maximum visibility for your research: over $100 \mathrm{M}$ website views per year

At BMC, research is always in progress.

Learn more biomedcentral.com/submissions 